\section{What is forward surgery?}

Forward surgery is the use of surgical techniques to resuscitate and stabilise a casualty which fulfils Rignault's concepts of multi-echelon surgery (1) allowing provision of mobile resuscitation with damage control surgery, with more definitive surgery after evacuation.

Forward surgery at Role 1, is part of resuscitation, it is not definitive surgery; if laparotomy and/or thoracotomy are required here then these casualties may need to be considered expectant (2), since such surgery will require too many resources.

To provide true front line surgery implies that all front line doctors are trained to this level of resuscitation. More practically, all the young RMOs with little medical experience would be returned to base hospitals as GDMOs and experienced clinicians with the required resuscitation skills moved into their place.

The resuscitated casualty requires ICU like transfer facilities in order not to die on the way to definitive surgery. Prompt evacuation to a definitive facility will be required in order not to waste the effort, and then life. The concept of providing a mobile level 1 trauma service to the front line with the definitive surgical facility, not being along the corridor, but at the next echelon, may be the answer.

Improved resuscitation will be a force multiplier and will demonstrate to the soldier and their family at home that their life is taken seriously and that levels of care that can be expected on the street in their home town can be exceeded.

The concept of forward surgical resuscitation can grow into a military reality with the appropriate doctrinal approach (3), but requires massive resources to implement such management standards at the front line (2) without the effort being wasted during casevac.

I am etc.

N Buxton

Department of Neurosurgery

University Hospital

Nottingham

NG7 2UH

\section{References}

1. Rignault DP. How to train war surgery specialists: Part 11. Military Medicine 1990; 155(4): 143-147

2. Butler FK, Hagmann JH. Tactical management of urban warfare casualties in special operations. Military Medicine 2000; 165(4): Suppl

3. Terrell AG. First line medical support: Sorting it out. FR Army Med Corps 2000; 146(3): 162-163

\section{Shaping the Battlespace - An Additional Role for the DMS?}

Gill highlights an additional role for the DMS on operations (1). Operation AGRICOLA saw medical personnel deliberately deployed to shape the battlespace. The early success of the mission depended on the main route into Kosovo remaining clear. Commander 5 Airborne Brigade deployed a small logistic team that included a medical element from 23 Parachute Field Ambulance (PFA); our mission was to encourage the local population to stay off the main route by providing food and medical support. In the event this was not needed, but it is worth noting that it was a small but important element of the 5 Airborne Brigade plan.

An additional role should also be considered; that of managing local medical resources. A failure to keep local medical facilities running could have a significant impact on the mission by overwhelming military medical facilities or through adverse media reporting.

A 23 PFA squadron commander was tasked with ensuring the key primary care facility in Lipljan continued to operate. This large four-storey building housed over 60 Serb primary care physicians serving an area the size of the Isle of Wight. The management structure was encouraged to change from allSerb to a mixed structure that was Albanian led; by pre-empting the Serb exodus seen elsewhere during the second week of the operation, the facility continued to deliver a full primary care service during the critical first month before the NGO effort became co-ordinated.

Pristina Hospital attempted to maintain the status quo of an all-Serb staff structure as Albanian medical staff returned; the overnight sabotage and exodus of many of these Serbs caused a final and complete collapse of secondary care for much of Kosovo. Subsequent restoration took considerable combined UK military and civilian effort (2).

There is clearly a role for medical personnel in shaping the battlespace; most importantly local politics and the media are likely to be both constraints and enablers in achieving success.

I am etc

Lt Col A N Williams RAMC Consultant Occupational Physician Army Medical Directorate

\section{References}

1. Gill RMF. The Roles of the Army Medical Services - Shaping the battlespace? f $R$ Army Med Corps 147:2.111-2. Jun 01

2. Redmond T. How do you eat an elephant? $B M F$. 1999 Dec 18-25; 319(7225): 1652-3. 